\title{
Heritage as a basis for creativity in Creative Industries: the case of Taste Industries
}

\section{Christian Barrère}

\section{Laboratoire Regards, Université de Reims Champagne Ardenne}

\begin{abstract}
:
The aim of this paper is to focus on the specificities of the creative processes in Taste Industries: industries that have connected the artistic and industrial dimensions to supply goods and services - demand for which derives not from the logic of needs and necessity, but from the logic of pleasures, tastes, ethic preferences and hedonism. These taste industries belong to the Creative Industries but, unlike scientific and technological production, they work not on the basis of cumulative knowledge (replacing goods by better quality amenities over time) but through the creation of ideas, drawings, recipes, goods and services which pass through time, and which constitute heritages. Thus, creativity works on the basis of heritages: that is, past and accumulated creativity. The paper considers how the different types of heritage (craftsmanship knowledge, creative knowledge, tastes, institutional heritage and common cultural heritage) contribute to creative process. It concludes on the double-edged effect of heritages, which while bestowing competitive advantages and favouring the development of creativity, do orient development along a given path, promoting a certain kind of creativity that may lead to lock-in effects, and build obstacles in the way of development.
\end{abstract}

Keywords: creativity, heritage, taste industries, creative industries, lock-in effects. 
1 The development of taste goods and taste industries

In contemporary societies, science and technology are increasingly significant, and lead to a great deal of innovation. Nevertheless, alongside the well-known trends of scientification, technologization and intellectualization of modern capitalism, artistic and cultural fields are evolving. Some areas - such as design, ready-to-wear and video games - combine the artistic and industrial dimensions. Some economists have proposed new categories to describe these new fields: cultural industries, creative industries and creative economy being the main ones. In this paper we consider industries that have connected the artistic and industrial dimensions yet which are often underestimated: fashion, perfume, gastronomy, tourism, wines and a few others. We call them Taste Industries (TI), because demand for their goods derives from the logic of tastes rather than that of needs and necessity. Then tastes refer to pleasures and hedonism but their distance from necessity also allows individuals to implement ethic values and social preferences. We can observe a remarkable expansion of the field of taste: taste for pleasures (from food to sport) that used to be vile is more and more legitimated. In all developed countries, consumption surveys show that the purchase of taste goods is taking on more and more importance in the family budget. Spending on tourism represents $9 \%$ of gross world product and 250 million jobs in the world, while spending on luxury industries amounts to more than $€ 200$ billion. Hirschman and Holbrook (Hirschman and Holbrook, 1982) introduced the idea of hedonistic consumption by distinguishing two main types of utility: a direct, material, instrumental or functional utility, deriving from necessity and needs, and a hedonist utility, related to pleasure and desire. Other sociological observations (Lipovetsky, 1987, 2006; Lebreton, 2002) on the changing practices of distinction, and on the search for identity1 have subsequently been incorporated into the theory (Cova and Cova, 2001) as new forms of an 'explosion of subjectivity' (Addis and Holbrook, 2001) that is characteristic of the contemporary period. On the other hand a lot of observations testify that individuals mix hedonic and moral considerations when they choose taste goods and services. They include their search for pleasure within metapreferences or values (Sen, 1977): they prefer tourism forms respecting the local populations, they choose green products, and they demand local produce and fair trade goods. The aim of this paper is to focus on the specificities of creative processes; in Taste Industries creativity works on the basis of heritages, i.e. past and accumulated creativity, which plays a key role.

2 Taste Industries as Creative Industries

1

Rochefort (2001) reports the increasing consumer demand for heritage, which is construed as a demand for stability. Consumers are anxious to rediscover their traditions, their history; they are looking for their 'roots'. Moreover, in a global world, consumers seek to be world citizens and consumers, to broaden their knowledge and understanding of other people and creations, and, particularly, their gastronomic creations. 
Taste goods industries use creativity and heritages 2 , even if they are organised in an industrial way. Let us consider the case of perfumes. Today, almost all perfume is produced industrially. Raw material costs for high-quality perfume represent approximately a tenth of their price. The value of a perfume does not, then, derive from material production costs but from its image, reputation, and distinctiveness. Perfumes associate creativity (that of a specially-trained and highly sensitive 'nez' whose skill is both specific and idiosyncratic) with an image bearing a high semiotic value. For instance Chanel $\mathrm{N}^{\circ} 5$ puts together a fragrance, a bottle, and the memory of Marilyn 3 and Coco Chanel.

A great many definitions of the creative industries have been suggested (Caves, 2000; Towse, 2003; Throsby, 2001; DCMS, 2001; KEA, 2006; and the French Ministry of Foreign Affairs) but none has been universally agreed-upon. We will, then, define the creative industries as those characterised by:

- $1^{\circ}$ An utilisation of serial production, which may be small-scale (for instance in gastronomy) or large-scale (mass production). For instance, in the field of ready-towear and accessories, Vuitton produced over three million bags a year. This is industrial-scale production, even if it does include skilled craftsmanship.

- $2^{\circ}$ The integration of creativity, either as an important productive input, or as the dominant one.

Nevertheless, within Creative Industries (CI) we have to distinguish between those using creativity including predominantly cumulative knowledge and those using creativity including predominantly non-cumulative knowledge. Science is the classic example of a field which makes use of creativity in the form of cumulative knowledge. Scientists use old scientific knowledge as input for the production of new knowledge that is more developed, more sophisticated, and more rigorous, so that the old knowledge melts, over time, into the new one, which ceases to have a value as such. On the other hand, noncumulative products of creativity also exist (Barrère and Chossat, 2004). This means that the production of certain specific creative goods does not aim at improving the knowledge of all, and will be replaced by better quality amenities in the future. Thus, creation will be included in both private and common cultural heritage. In other words, we can say that, in those fields governed by cumulative knowledge, heritages are fungible - whereas, in those fields governed by non-cumulative knowledge, they are not.

So the figure 1 represents creative industries on the basis of the Throsby's representation (Throsby, 2001) but including the role of heritages and distinguishing

2

We use the word "heritage" in a meaning different from the one generally used. Heritages include not only "official" and "institutional" heritages as museums, libraries, archaeological and historic sites, archives, and so on but also all the heritages made by the accumulation and sedimentation of creativity: for instance the heritage of know-how constituted in the Maison de couture or the recipes characteristic of culinary cultures.

3 Marilyn Monroe famously told a reporter in 1954 that all she wore in bed was "five drops of Chanel $\mathrm{N}^{\circ} 5$," thereby creating millions of fantasies among her own admirers and long lines at department store perfume counters in the USA. 
cumulative and no-cumulative knowledge. We include CI in an ellipse to focus on both sources of productive characteristics of Creative Industries. Both foci of the ellipse are the cumulative knowledge and the non-cumulative knowledge. Industries are more or less close to them. Around the first focus (cumulative knowledge) there is a first circle corresponding to science and technology (ST in the figure), and a second circle for heritages $(\mathrm{H})$; this circle is little because these heritages are fungible, being generally quickly integrated to the developments of science and technology. Around the second focus (no-cumulative knowledge) there is a first circle with arts and a second one corresponding to heritages, bigger than in the case of science and technology because they can remain for a long time a source of utilities and creativity. The Creative Industries are located according two criteria: their distance to each focus, their connection to craft processes or to industrial processes. 
Figure 1 Creative Industries

\section{Craft}

Wines

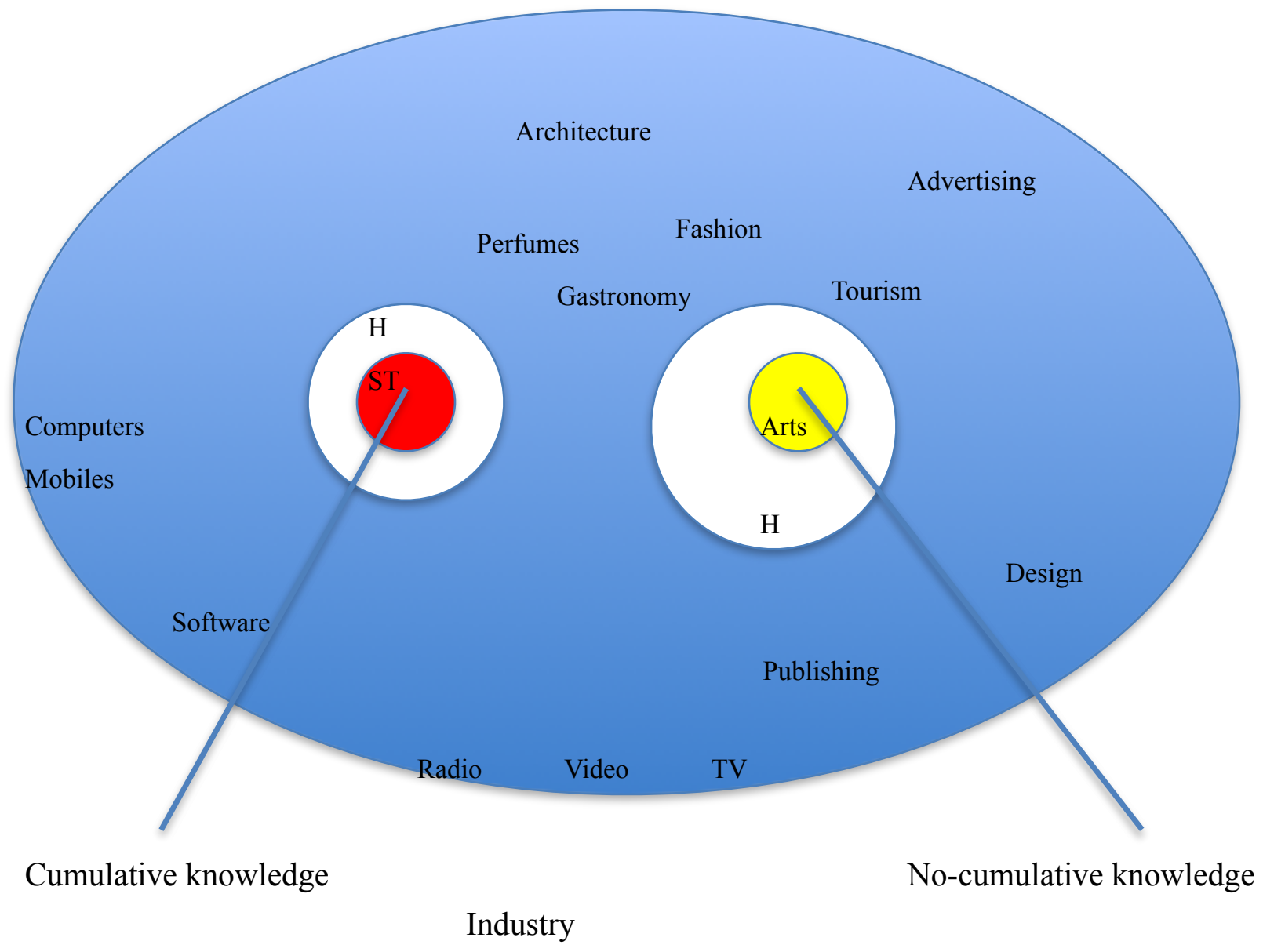

Within CI, Taste Industries group together industries producing goods and services the dominant characteristics of which are connected to tastes, pleasure and subjective choices4. They constitute a specific category of $\mathrm{CI}$ in that here, creativity relies heavily on heritages, in terms of both supply and demand. Taste goods are semiotic goods, since they carry a semiotic utility in addition to the material utility that is related to their substantial characteristics - to nourish, dress, protect from the cold, to entertain, etc. Demand for them is not sustained by need, but rather refers to desires and social values.

4 Today the majority of goods include a lot of characteristics, among which some taste characteristics. For instance car industry supplies cars with sophisticated design to appeal to consumers' tastes. Nevertheless, for almost people, cars remain utilitarian goods. Addis and Holbrook (2001) distinguish 'utilitarian products', 'hedonic products', and 'balanced products'. Taste Industries refer to hedonic products. 
According to the logic of desire, the demand is constantly in need of renewal - which can only be conjured up through the use of creativity. At the same time taste goods carry signs representing meaning and senses, which are cultural and embedded in a culture. Ferdinand de Saussure, the founder of semiotics, conceived the principle of 'the arbitrary of the sign': there is no natural and intrinsic relation between the signifiant (sign) and the signifié (meaning) but only a systemic one. Fischler (1999) argues that the distinction between edible and inedible, which seems so natural and instinctive, varies from country to country and from one culinary culture to the next: in 42 cultures, dog is commonly eaten, in many others, rats are very much appreciated, ants are cooked in Colombia, and bees, wasps and cockroaches in China. Taste goods are therefore connected to a culture and a past, linking people to their roots: to their own distinctive cultural heritage. Moreover, the presence of moral or ethic values within the motives of demands reinforces the demand for connecting goods and services to some cultural heritages, traditional social values and, on the contrary, new or foreign social values. The development of tourism based on cultural heritage shows the importance and the complexity of the 'demands for heritages' (Tunbridge and Ashworth, 1996; Graham and Howard, 2008; Harrison, 2012), the development of a 'memory industry' (Klein, 2000) and the commodification of heritages.

To satisfy the demand for novelty and creativity, suppliers have to develop creativity injecting more and more creativity into the goods. Creatively-driven competition tends to accelerate the rhythm of creation. For a long time the principle of two collections a year (autumn/winter and spring/summer) held sway over the fashion industry. Today, although the world of haute couture maintains this rhythm, ready-to-wear and a fortiori street fashion (Zara, H\&M, etc.) multiply the collections; Zara renews its stock twice a month, which implies a totally different way of creating and producing! It is the same in the gastronomic field where the chefs change their menus more often, and where famous French pastry cook Pierre Hermé offers cake collections to suit the season. More generally, taste industries have adopted the principle of systematic and regular renewal that started in the world of fashion, and competition drives a race towards creativity.

As was already the case in the world of art, creativity has now become the watchword in the taste industries. Since the last century, the great painter or musician has not been the one with 'superior' technical ability but the one who brings something new. It is now the same for taste industries. In gastronomy, the great chef is no longer he who cooks lièvre à la royale to perfection, but rather the who combines flavours or products in new ways. In fashion, the famous couturier is not the one who was best at drawing or sewing. Suppliers use their specific advantages and their heritages as input to help them keep up in this race towards creativity.

3 Heritage-inspired creative production

In the TI area, there are two distinct forms of culture: that which is 'new', which comes about through creativity, and that which is 'old', which draws from stock - through 
heritage. So, current creativity uses the creativity of the past - which has accumulated, constituting a heritage - and at the same time, adds to it. Moreover, when cultural industries use creativity and heritage simultaneously, they benefit from a virtuous circle, by which I mean that goods, knowledge, and ideas produced constitute types of heritage which, in return, favour creativity. We will mainly consider the cases of haute couture and gastronomy, although similar observations can be advanced in other TI.

Heritages can be private or common:

1. A heritage of craftsmanship, which has been handed down over generations of workers, providing them with the technical skill to perform sophisticated operations arising out of a long succession of inventions and innovations. When Christian Lacroix opened his couture house in 1986 he needed highly skilled workers, and had to deal with highly-specialized workshops producing pearls, embroidery, buttons, trimmings, and handmade textiles (Laver, 1995). In gastronomy, to become first-class chefs and propose sophisticated and creative dishes, cooks need the support of top teams of suppliers offering the finest products (meat, butter, vegetable, etc.) and highly skilled cooks. The importance of craftsmanship heritage is attested to by the behaviour of the leading firms in luxury accessories such as Vuitton, Hermès, Gucci and Prada. They limit the use of outsourcing, seeking to set up plants in places that are rich in highly-qualified labour. In the same way, analysis of industrial districts (Santagata, 2011) showed - in the case of Italian districts, for instance - how the social heritage of craftsmanship has constituted a key condition for economic and social development.

2. A heritage of creative knowledge. On the one hand, this is a private heritage. The history of the Maison de couture, the great designers (Chanel, Balenciaga, Dior, Saint Laurent) and the cult of creation are a major incentive to creativity. This heritage develops both a 'stock and memory' and an 'experience' effect (apprenticeship from famous masters in the Maison or the Grand restaurant, which facilitates the transmission of creativity, especially between generations). It takes the specific form of private heritages of creative products. In the fashion industry this constitutes both a physical stock of designs and models and the cultural heritage of a style (e.g. the Chanel style). When Lagerfeld became director of Chanel, his first decision was to spend a lot of time visiting all the departments of the Chanel Maison, so as to be impregnated by its heritage. He sought, not to copy Chanel, but to be inspired by the Chanel style, so as to create a new Chanel in the style of Coco Chanel5. This is extremely valuable, because not only does it allow new designers to 'revisit' both old collections and styles and the history of fashion, but also because it allows customers to identify a style. On the other hand it is a

5 Roux E (2001) La conciliation des contraires : créativité et rigueur dans la gestion de l'identité d'une marque, communication to the workshop La mode, un laboratoire de créativité, Turin, ICER, octobre 2001. 
common heritage of creative knowledge, which also produces experience effects. Yves Saint Laurent was just 21 when he succeeded Christian Dior upon his death. His first collection - the Trapeze line - which was under the critical spotlight, demonstrated a vast culture as well as an ability to fit into the rhythm of fashion. In the UK, the success of Vivienne Westwood or John Galliano is linked to the tradition of English tailors (Lehnert, 2000). Creative heritage is also the ability to design new luxury goods, closely-related to haute couture, and so to widen the product range. Old styles are the basis for new variations. Yesterday's fashion echoes the 1970s; tomorrow, it may echo the 1940s, and so on. Ralph Lauren and Calvin Klein have been inspired by English aristocratic fashion and, for casual and sportswear, by American pioneers' style. The gastronomic industry is in a similar situation. Chefs have a huge stock of recipes. They can introduce creativity into their dishes by 'revisiting' old recipes. Foreign heritages are often used to join traditions together, thus renewing them. Heritage therefore plays a key role as a source of inspiration, production and contemporary creativity.

3. A heritage of tastes, i.e. a semiotic heritage. This contributes to creation but also plays on demand. The existence of a heritage of tastes and preferences, i.e. a common reading of signs, produces homogeneous representations. In a market of sign-goods such as the fashion or gastronomy market, it allows demand to adjust to supply, since creativity does not correspond to alignment on individual preferences but more to the production of new goods, previously unknown to consumers, and new wants. It makes fashion and gastronomic dishes understandable; it makes creation credible; it legitimates the creative work as fashion creation or as gastronomic creation. Moreover, it provides a competitive edge on world markets. The semiotic heritage leads to an image heritage. All French and Italian products benefit from the image effect of French and Italian gastronomies. The industrial luxury groups value their semiotic heritage in the form of the trademark. The trademark becomes a symbol of distinction between ordinary and extraordinary goods. It joins a traditional legitimacy to the rationalist (an extra-quality) and the charismatic ones (the legend of the great creators, Christian Dior, Giorgio Armani, Coco Chanel, Paul Bocuse...). Bernard Arnault, the owner of LVMH, used to say that Louis Vuitton has a 150-year history. Some economists (e.g. Rochefort, 2001) report an increasing consumer demand for heritage, which is construed as a demand for stability. Consumers are anxious to rediscover their traditions, their history; they are looking for their 'roots'.

4. An institutional heritage. The French institutional heritage of Haute Couture and the Italian institutional heritage of Alta Moda include public policies to improve art, fashion and creativity, trade associations, and more significantly, the institutional form of the Maison de haute couture, which occupies the key position - meaning creativity also plays a key role. This boosts the incentive to be creative, in the fields of both production and management, and tends to 
organize strategies by pairing the famous creator with a famous manager (Yves Saint Laurent and Pierre Bergé, Muccia Prada and Patrizio Bertelli). In gastronomy, this history of grands restaurants is closely associated with the legend of grands chefs who entered the pantheon of gastronomy, developing the cult of creation - and representing a major incentive to creativity.

5. The Taste Industries use common cultural heritage as a background for creation. Sometimes, the influence of cultural heritage is very direct; for instance when Saint Laurent created his Mondrian collection or when Watteau inspired Lagerfeld's new models - including the famous White Pierrot costume. Moreover, a creative district emerges, allowing innovations to circulate among the arts, and emulating creativity. Local creation can also take advantage of other cultural heritages. Issey Miyake uses his Japanese culture to work on pleated textiles - invented by Fortuny, but now developed with synthetic substances - and is influenced by origami and samurai armour.

4 Concluding remarks: The double-edged effect of heritages

Heritages bestow competitive advantages and favour the development of creativity. This explains the existence of creative districts (Santagata, 2011), milieu (Tornqvist, 1983) and cities (Florida, 2002). They do however orient this development along a given path, promoting a certain kind of creativity that may build obstacles to development. While they generally encourage innovation and creation, in some cases they may lock development in, in the sense used by North (1991), and, eventually, curb creativity.

In Taste Industries, we can observe periods that reveal a changing combination of both effects. In a first time heritage had mainly a conservative effect, according to the system of guilds. Craftsmen had to produce goods legitimated by the past according to the traditional routines. In a second time the competition between producers led some of them to innovate. As technical innovations are limited because the production mainly depended on handicraft processes, novelty implied becoming creative. For instance Aristocratic cuisine was conservative; the same dishes remained the symbols of luxury and distinguished them from the ordinary popular cuisine. But the society of the Court (Elias, 1973) drastically changed things. To dazzle the Grands, the Grand Cuisinier resorted to creativity: new recipes, new presentations, and new sauces. For that, he sought inspiration from the pre-existing gastronomic heritages, but adding new recipes, he contributed to its expansion and reproduction. His name and his personality were included into the history of cuisine and melt into the aristocratic gastronomy. In the fashion industry Charles Worth declared he was an "artist in dresses"; so the supply was in command of the exchange process. Supply was no more a response to previous demands or the consequence of previous models (given by the étiquette and the tradition). The artist was the starting point and introduced novelty to become a leader in the competition between suppliers. 
Today strong and structured heritages institutionalize given practices and given tastes, and, thus, create barriers to changes; lock-in phenomena are developing. Some creators continue heritage-inspired creation without adding new ideas or using new sources of inspiration. They develop a conservative creation that might decrease the value of heritages. Others seek to modify old heritages.

In the gastronomic field for instance, some chefs (mainly in France, where the aristocratic heritage is peculiarly strong) continue using, as main or unique source of inspiration, the gastronomic heritage of aristocratic cuisine. At the same time, other chefs consider the elitist restaurant to no longer be the single dominant model, developing new kinds of gastronomy. Alain Senderens extols the virtues of 'low-cost gastronomy' based on creativity mixed with ordinary foodstuffs and settings, able to attract a wider, lesswell-off clientele, looking for new codes such as pure and healthy products, less sophisticated settings and so on. Newly-famous chefs of North European countries offer new cuisines based on natural products, new flavours from herbs and aromatic plants, highlighting new culinary heritages, promoting multiculturalism and world fusion gastronomy.

Lock-in effects can affect the whole range of innovations, including managerial ones. It is interesting to consider how the main innovations in the management of the fashion process emerged not in the two main 'fashion' countries - Italy and France- but rather in Spain (Zara) and Sweden (H\&M).

The management of organisational rent leads to similar risks. Heritages are strategic assets which give a specific advantage and, thus, an organisational rent. Instead of being reinvested to produce new creativity, organisational rent may be used for other goals; then, the organisation gradually fades, creativity decreases and the virtuous heritage-creativity circle turns into a vicious one. For instance, luxury groups are tormented by the desire to invest in distribution networks, especially to take positions in emerging markets, and the cost of investing in creativity.

Taste Industries therefore demonstrate that heritages, while playing an essential role in the renewal of creativity, are nonetheless in need of appropriate strategies.

\section{References}

Addis M, Holbrook MB (2001) On the conceptual link between mass customisation and experiential consumption: An explosion of subjectivity. Journal of Consumer Behaviour 1/1: 50-66.

Barrère C, Chossat V (2004) Intellectual Property Rights and Cultural Heritage ; The Case of Non-Cumulative and Non-Degenerative Creation. RERCI 2004, 1/2: 97-117.

Caves RE (2000) Creative Industries. Contracts between Art and Commerce. Harvard University Press, Cambridge. 
Cova V, Cova B (2001) Alternatives marketing : réponses marketing aux évolutions récentes des consommateurs. Dunod, Paris.

DCMS (2001) UK Government Department for Culture, Media and Sport. Annual Report 2001. www.culture.gov.uk/. Accessed 12 June 2012.

Fischler C (1993) L'homnivore. O. Jacob, Paris.

Florida R (2002) The Rise of the Creative Class. And How It's Transforming Work, Leisure and Everyday Life. Basic Books, New York.

Graham B, Howard P (edt. by) (2008) The Ashgate Research Companion to Heritage and Identity. Ashgate Publishing, Farnham.

Harrison R (2012) Heritage: Critical Approaches. Routledge, London.

Hirschman EC, Holbrook MB, (1982) Hedonic Consumption: emerging concepts, methods and propositions. J MARKETING 46/3 : 92-101.

KEA (2006) The economy of culture in Europe. Study prepared for the European Commission (Directorate-General for Education and Culture). www.keanet.eu/ ecoculture/studynew.pdf. Accessed 14 June 2012.

Klein B (2000) The Moral Content of Tradition. Homecraft, Ethnology, and Swedish Life in the Twentieth Century. WESTERN FOLKLORE 59:171-195.

Laver J (1995) A Concise History of Costume. Thames and Hudson, London.

Lehnert G (2000) Histoire de la mode au XX ${ }^{\circ}$ siècle, édition française. Könemann, Paris.

Le Breton D (2002) Signes d'identité. Tatouages, piercings et autres marques corporelles. Métailié, Paris.

Lipovetsky G (1987) L'empire de l'éphémère. Gallimard, Paris.

Lipovetsky G (2006) Le bonheur paradoxal. Gallimard, Paris.

Ministère des Affaires étrangères et européennes (2009) Rapport Industries culturelles et Ministère des affaires étrangères et européennes. www.diplomatie.gouv.fr/.../ 091005. Accessed 14 June 2012.

North D (1991) Institutions, Institutional Change and Economic Performance. Cambridge University Press, Cambridge.

Rochefort R (2001) La société des consommateurs. Odile Jacob, Paris.

Santagata W (2011) The Culture Factory. Creativity and the Production of Culture. Springer, Heidelberg.

Sen AK (1977) Rational Fools: A Critique of the Behavioral Foundations of Economic Theory. ROY I PHS 6/4: 317-344.

Throsby D (2001) Economics and Culture. Cambridge University Press, Cambridge.

Tornqvist G (1983) Creativity and the renewal of regional life; in A. Buttimer (ed.) Creativity and Context: A Seminar Report, 91-112, Lund Studies in Geography. B. Human Geography, N`50 Lund: Gleerup.

Towse R (2003) A Handbook of Cultural Economics. Edward Elgar, Cheltenham.

Tunbridge JE, Ashworth GJ (1996) Dissonant heritage: the management of the past as a resource in conflict. John Wiley and Sons, Chichester. 